\title{
La representación del instante: Lessing y el método pictográfico de Ernst Gombrich
}

\section{The representation of an instant: Lessing and Ernst Gombrich's pictographic method}

\author{
Ignacio URibe Martínez \\ Instituto de Filosofía. Pontificia Universidad Católica de Valparaíso \\ ignacio.uribe@ucv.cl
}

Recibido: 16 de mayo de 2011

Aprobado: 19 de octubre de 2011

\begin{abstract}
Resumen
La representación del instante como límite propio de las artes figurativas en el Laocoonte de Gotthold Ephraim Lessing, ha sido asumida por Ernst Gombrich como una concepción falaz del arte. Sin embargo, a partir de la consideración de la imaginación y la idea de verosimilitud, el presente artículo pretende demostrar una afinidad entre el concepto de "método pictográfico" desarrollado por el historiador austriaco y los postulados fijados en la obra del pensador alemán.

Palabras Clave: Instante, método pictográfico, verosimilitud, imaginación.
\end{abstract}

Uribe Martínez, I. 2011: La representación del instante: Lessing y el método pictográfico de Ernst Gombrich, 24(1), 91-101

\begin{abstract}
Although the representation of a single instant as a limitation to figurative arts in Lessing's Laokoon has been considered by Ernst Gombrich as the origin of a fallacious conception of art, this article shows the affinity between the idea of "pictographic method" displayed by the Austrian historian and the notions of imagination and verisimilitude proposed by Lessing.
\end{abstract}

Key Words: Instant, pictographic method, verisimilitude, imagination.

Uribe Martínez, I. 2011: The representation of an instant: Lessing and Ernst Gombrich's pictographic method, 24(1), 91-101

Sumario: 1. Introducción, 2. La representación del instante: espectador e imaginación, 2.1 Lessing y Hogarth: la imaginación a través de los ojos, 2.2 El instante idóneo: narración y descripción, 3. El método pictográfico de Ernst Gombrich, 4. Conclusiones Referencias

\section{Introducción}

Comencemos apelando a la imaginación a través de la descripción de dos cuadros. El primero es una escena en la que se encuentran dos personas en un cuarto. El espacio está teñido solamente por una tenue luz que el pintor ha utilizado como recurso de contraste para resaltar los dos personajes que ocupan el centro de ella. A la derecha una ventana rectangular termina sobre un escritorio a punto de caer frente al cual hay una cama. Sentado en ella, entre ambos muebles, un hombre intenta atraer hacia sí una 
mujer tomándola por la parte inferior del vestido. Ella se resiste con su brazo derecho empujando la cabeza del hombre, mientras con el izquierdo provoca la inclinación de la mesa y la abertura de un cajón que contiene un libro acerca de la reglas de cortesía. La mirada de la mujer sigue la dirección del rechazo. Una caja y un espejo que caen por la inclinación del mueble acentúan la instantaneidad de la representación. Sólo un pequeño perro en la parte inferior, a la derecha del cuadro, será el testigo ocular del acto.

Las conjeturas que podemos hacer a partir de esta descripción pueden ser infinitas. Para algunos la connotación abusiva de la actitud del hombre explicará plenamente la resistencia de la mujer; para otros la narración podría seguir una línea más sentimental: aquello que aparece representado es un tierno intento de reconciliación al que la mujer, indignada, se resiste. Cualquiera que ella sea, inevitablemente la imaginación queda concentrada en el momento preciso que el artista ha puesto en escena y las disquisiciones permanecerán en el espacio temporal que el pintor ha presentado. Sea cual fuese nuestra lectura, siempre los límites temporales estarán demarcados por el instante.

En la escena siguiente vemos al hombre de pie, arreglándose los pantalones. En una silenciosa actitud escucha a la mujer que pareciera suplicarle algo. Esta vez, ella aparece sentada en la cama mientras acerca al amante con su mano derecha, obligándolo a reclinarse hacia su persona. Parece hablarle al mismo tiempo que se arregla el vestido. La caja yace en el suelo, abierta. El perro, que no sabemos si duerme o está aturdido por el golpe de la mesa que se le venía encima, está tendido junto a los restos del espejo, al costado de la mesa volcada.

En este caso las especulaciones podrían, en primera instancia, llevarnos a explicar el momento precedente al representado. Las razones que podemos aducir para comprender o llenar los espacios vacíos de la historia que se nos presenta, cambian junto con la demarcación temporal de la escena. El instante se vuelve más ambiguo, especialmente porque la palabra hace su entrada. El gesto ya no basta pues la conversación tiene un argumento que seguirá siendo por siempre desconocido. En ese sentido, pasado, presente y futuro irrumpen en el terreno de la pintura. El hecho ya consumado y la actitud de diálogo rompen el instante, la plática versará sobre lo acaecido. La gestualidad comporta la palabra, y en su actuar como medio de expresión, amplía el marco temporal.

En la descripción de estas dos obras quedan expuestos algunos de los problemas que abordó Gotthold Ephraim Lessing en su Laocoonte (1766) en relación al gesto, el instante y la imaginación. Ambas, conocidas como Antes y Después, se conservan hoy en Los Ángeles - en el Getty Museum - y fueron pintadas por William Hogarth entre 1730 y 1731 por encargo del duque de Montague (Nichols, 1785: 233). Desde ahí pretendemos abordar una eventual relación con el concepto de método pictográfico utilizado por Ernst Gombrich, mostrando que las leyes lessinianas para la representación del instante en el arte y la propuesta de Gombrich tienen sólo una distancia aparente; en otras palabras, es posible hacer una lectura del Laocoonte que comulgue con el planteamiento del historiador vienés. 


\section{La representación del instante: espectador e imaginación}

Desmond Morris distinguió el gesto en la pintura como ilustrativo y emblemático. El primero es aquél que acompaña una exposición ilustrándola: por ejemplo, los movimientos figurativos que puede realizar un profesor de geometría para proyectar en sus alumnos ciertos problemas a través de formas dibujadas en el aire, o los movimientos de la mujer de Hogarth que nos ayudan a adivinar lo que dice. El emblemático, en cambio, es una acción que reemplaza el discurso. Esencialmente son gestos "simbólicos" que como tales "implican un proceso de abstracción", por ejemplo levantar la mano a manera de saludo (Morris, 1981: xvi-xvii), o el giro de la cabeza que deja ver el rechazo de la mujer en la primera escena descrita al inicio. Este aspecto simbólico del gesto se vincula con una expresión subyacente en la obra de arte que el observador puede imaginar desde los indicios plasmados por el artista.

\subsection{Lessing y Hogarth: la imaginación a través de los ojos}

En el libro segundo de su estudio acerca de los límites de la pintura y la poesía, Lessing establece como fuente de la creación artística en la Antigüedad la emoción en general y el amor en particular:

Sea historia o leyenda aquello de que el amor fue el que movió al hombre a dar sus primeros pasos en las artes plásticas, lo que sí es cierto es que nunca se cansó de dirigir la mano de los grandes maestros de la Antigüedad. Porque, si hoy en día la pintura, como arte de representar cuerpos en una superficie, se practica en todo el alcance que esta definición entraña, antiguamente la sabiduría de los griegos había puesto fronteras mucho más estrechas a este arte limitándolo a la mera representación de cuerpos hermosos. (1990: 13)

La silueta de una sombra que luego fue moldeada en un bajorrelieve para recordar al amante, es la referencia a Plinio que Lessing utiliza para referirse a la reciprocidad entre la obra y el espectador: el arte nació del amor a condición que el espectador fuese capaz de evocarlo con la mirada. Asimismo el sentimiento amoroso queda ineludiblemente unido a la finalidad del arte, el placer de lo bello. A pesar que Lessing no era un platónico, la doctrina del filósofo griego acerca del amor permite precisar sus planteamientos; si cada auténtico amor debe ser amor creativo, la energía espiritual que Lessing exige a la pintura irrumpe precisamente en el momento en que se origina, podemos decir, cuando se hace verosímil (Cfr. Cassirer, 2003). Ahora bien, siendo el placer el fin del arte según Lessing (1990: 15), y encontrándose éste en el espacio de las similitudes, entre la sensibilidad y el intelecto, entre el acto y la intención, la belleza entonces no puede quedar sujeta ni a una ni a otra. La función de la imaginación queda así delimitada a partir de la figura que el artista presenta: "[...] porque lo que encontramos bello en una obra de arte no son nuestros ojos los que lo encuentran bello, sino nuestra imaginación a través de nuestros ojos" (Lessing, 1990: 53) 
La visión se transforma en un medio que transporta al espectador hacia una identificación con la emoción expresada, la que a su vez se encuentra insinuada en la obra. El sentido visual es sólo el medio para una imagen que encuentra asidero en el intelecto gracias a la imaginación. Por esta misma razón, la expresión no debe ser más que un contorno que siga los pasos de la apariencia, alejándose de los peligrosos desbordes emotivos provocados por la representación intensa del sentimiento, como ocurre, por ejemplo, cuando los rasgos de la cara se marcan acusadamente si es demasiado profundo el afecto que expresan (Lessing, 1990: 16-19). Ello se traduciría en una violencia contraria a la búsqueda de lo bello, a la vez que impediría al espectador usar su imaginación ya que todo le vendría dado.

Lessing, quien tradujo The Analysis of Beauty de Hogarth en 1754, probablemente tenía presente el texto cuando escribió el Laocoonte. La importancia que Hogarth daba a la imaginación queda establecida desde el inicio de la obra. Allí el contorno, o la línea, como dice el pintor, es fundamento imaginativo. La consideración de objetos compuestos por ella, permite obtener un claro concepto de los límites de una figura. Así:

Quien sea capaz de soportar la dificultad de hacerse una clara idea de las distancias, relaciones, y oposiciones de los distintos puntos y lineas de las superficies, incluso de las figuras más irregulares, gradualmente llegará a recordarlas aunque no se encuentre frente a ellas. (Hogarth, 1997: 22)

Hogarth busca asistir al pintor en la creación de imágenes de la misma forma como la obra debe guiar la imaginación del observador a partir del recuerdo del pintor, o, como afirma Lessing, del recuerdo de la figura del amante.

\subsection{El instante idóneo: narración y descripción}

La presencia de Hogarth en el Laocoonte puede ser precisada de una manera que nos permite volver al problema de la expresión. En el capítulo XV, dedicado al rostro, el pintor inglés afirma que hay expresiones que pueden ser profundamente desagradables, como cuando la suave sinuosidad de las líneas que conforman una agradable sonrisa cerca de las esquinas de la boca, pierde su belleza en la carcajada (Hogarth, 1997: 98-99). Algo similar sucede con el movimiento. A pesar que un rápido movimiento da vivacidad a las partes del cuerpo, un movimiento lento otorga solemnidad y peso a la acción, permitiendo al mismo tiempo que el ojo capte la gracia de las líneas (Hogarth, 1997: 105-106). Quien represente figuras danzantes deberá fijar a cada persona en un instante, como suspendida en la acción (Hogarth, 1997: 103). El movimiento se hace así comprensible para el ojo ya que el cuerpo no sobrepasa los límites de la expresividad pictórica. En Hogarth quedaba de esta manera prefigurado claramente el problema de la elección del instante más idóneo para ser representado. Sobre él, dice Lessing: 
En sus composiciones, que implican coexistencia de elementos, la pintura solamente puede utilizar un único momento de la acción; de ahí que tenga que elegir el más idóneo de todos, aquel que permita hacerse cargo lo mejor posible del momento que precede y del que sigue. (1990: 106-107)

Para Lessing el tiempo es el dominio del poeta, como el espacio es dominio del pintor. La yuxtaposición de dos momentos en una misma representación era, por lo tanto, una imperdonable invasión del pintor en los dominios del poeta "que el buen gusto no puede aprobar jamás". El poeta debía ocuparse de la sucesión de los objetos o sus partes, es decir, de las acciones; mientras en la pintura, debía primar el espacio. Criticaba así Lessing a Tiziano, quien al representar completa la historia del hijo pródigo, su vida de disipación, su pobreza y arrepentimiento, había violado las leyes de su propio arte (1990: 120). Los objetos que en la pintura coexisten lo hacen en un tiempo determinado, de tal manera que cada representación correspondería a un eslabón de la cadena temporal. La pintura, en razón de los signos que emplea o de los medios de imitación de que dispone, debe renunciar al tiempo. El pintor debe contentarse únicamente con pintar acciones simultáneas (Lessing, 1990: 105).

Si la génesis de las artes plásticas se encuentra en la narración como fuente de sentimientos, y ella está fundada en una emoción, que a su vez no puede ser plenamente expresada por el artista, entonces el pathos de las figuras debe mostrarse en un movimiento corporal que resulte evocativo y controlado. El gesto no sólo se convierte en un símbolo difícil de manejar por parte del artista, sino también en la manifestación de un instante que surge como expresión de la emoción (Cfr. Chastel, 2002). Pero, ¿de qué forma podría la pintura, si su fuente es el sentimiento, lograr ser un indicio de lo verosímil sin con ello desvirtuarse a sí misma engañando al espectador?

A modo de premisa, podríamos establecer que la representación del momento más fecundo corresponde siempre a una descripción; en ella, el objeto que se delinea buscará siempre configurar de la manera más acabada posible una idea:

Homero no pinta el escudo [de Aquiles] como algo que está ya listo y terminado, sino como algo que está haciéndose. También en este caso se ha servido del famoso artificio que consiste en transformar en sucesivo lo que en el objeto que quiere presentar es simultáneo, y hacer así de la pintura aburrida de un objeto el cuadro vivo de una acción. Lo que estamos viendo no es el escudo, sino el artista divino ocupado en la fabricación de éste. (Lessing, 1990: 124)

La descripción de Homero, a diferencia del escudo como obra artística, rompe con la simultaneidad, da cuenta de los pasos de la elaboración (Carter, 1924: 397). No sucede lo mismo con el artista. Si éste quisiera pintar los versos de Homero, se vería obligado a seguir el camino contrario, es decir, volver al instante de la concreción, cuando lo simultáneo se aúna en la imagen artística. Pero como ya sabemos, ello no basta para delimitar el instante propio del arte figurativo. La descripción debe ir acompañada de una comprensión de lo que precede y de lo que sigue al momento representado, labor que cumple la imaginación como narración. Si la descripción se 
encuentra aparentemente siempre presente en la obra de arte, la narración, particularmente en la obra de Lessing, no es excluida a condición que permanezca ligada a la fuerza descriptiva (Alpers, 1976: 16). En otras palabras la descripción, en el Laocoonte, puede ser leída como el gesto delicado de un instante que apunta a la lectura silenciosa de lo que ha ocurrido y de lo que vendrá, una comunicación muda entre la evocación y la especulación. La narración, en cambio, correspondería a la imaginación del observador. A éste queda la función de deducir, a partir de lo descrito, la emoción que el artista ha entregado veladamente (Lessing, 1990: 130)

Los ejemplos que hemos presentado al comienzo nos permiten comprender los problemas aquí mencionados. Las obras de Hogarth no tratan un tema que nos sea familiar, como una escena bíblica o una leyenda; por el contrario, estamos completamente en la oscuridad y el pintor se limita a describir. Al quedar atrapados en el presente buscando una explicación del momento, la narración imaginativa no logra desarrollarse. Por este camino, el gesto en su ambigüedad es incapaz de dar paso a la emoción pues no sabemos con certeza qué enfrentamos. Pero, podríamos preguntar, ¿es condición sine qua non que todo sea evidente?, ¿no convertiría ello al observador en un sujeto pasivo? Desde la perspectiva de Lessing no, porque es precisamente la verosimilitud de la obra la que exige la participación de la imaginación. Así como lo leído se vuelve vida en el pensamiento de Lessing gracias a su comprensión apasionada (Kommerell, 1990: 16), lo visto se vivifica imaginativamente, se vuelve certeza. La imagen en general y la expresión en particular son indicios que no pueden contradecir el todo de la obra. El placer no sólo radica en la belleza de la forma, también se hace vivo en el reconocimiento a partir del rastro. Mientras más claro éste sea, más clara habrá sido la elección del instante y con mayor riqueza se habrá expresado la libertad del artista. Esta última, en la similitud de la forma, apuntaría hacia una reconciliación con la verdad, el rastro descriptivo tendería a la narración imaginada. En la pintura como conjetura es donde la imagen indiciaria del pintor y la imaginación del espectador se encuentran para alcanzar una verdad a partir de la similitud.

La distinción entre la belleza de la forma y la obra como huella, se hace más transparente en la idea que Cassirer tenía de Lessing. Para aquél, el pensamiento de Lessing no apuntaba a la relación lógica de los conceptos, sino a que cada uno de ellos, en sí mismo, era utilizado de una manera que permitía comprenderlo y explicarlo en su fondo vital: "Lo decisivo en esta aportación no es la materia del concepto como tal, sino su forma, no su qué en el sentido de la definición lógica, sino su trasfondo espiritual" (Cassirer, 1994: 388-89). Un paralelo con la forma artística apuntaría hacia la misma dirección, lo representado muestra su linfa vital cada vez que la forma logra ser expresión de su valor propio, cuando la comunicación se manifiesta en la imagen del gesto puramente espiritual.

\section{El método pictográfico de Ernst Gombrich}

Imaginando las dificultades que Lessing podría haber encontrado en las obras de Hogarth que hemos descrito, se hace necesario preguntar de qué forma podría comprenderse la narración en la obra sin que forzosamente contenga una yuxtaposición de momentos. Una primera respuesta estaría dada por la función que cumple la ima- 
ginación, pero ello podría inducir a un error cuando el espectador desconoce el tema representado. Junto a lo anterior asoma el problema de cómo puede la narración hacerse presente sin transgredir los preceptos de Lessing en torno a la expresión de los sentimientos como fuente de la creación artística. Creemos que la respuesta puede ser abordada desde el concepto de método pictográfico analizado por Gombrich.

Según el historiador del arte vienés, el método pictográfico es aquel estilo en pintura que reúne en la representación de un momento, una historia ya consumada. A partir de una yuxtaposición equiparable a una breve narración, el pintor describe por medio de los gestos y la disposición espacial, un momento que logra evocar en la imaginación del espectador una secuencia de la que se tiene sólo un indicio (2000: 88-89). Desde una primera aproximación, el método pictográfico implicaría entonces tanto la descripción como la narración; sin embargo aparece como elemento distintivo una acción ya ejecutada que está siendo narrada. Es necesario aquí hacer una aclaración para no confundir el concepto presentado por Gombrich con lo que en historia del arte se conoce con el nombre de "contracción iconográfica". Ésta corresponde a un principio compositivo elegantemente cincelado a partir del cual se logra sintetizar en una sola figura, diversos momentos de una historia (Settis, 1990: 72). Imaginemos que las escenas de Hogarth fuesen reunidas en un solo instante. Pensemos en el hombre con sus ropas desabrochadas forcejeando con la mujer, quien podría conservar el gesto de arrepentimiento. La escena se haría más difícil de comprender puesto que sería complejo interpretar la compunción junto a la violencia. Pero podemos también imaginar al hombre acercándose a la mujer y a ella intentando detenerlo con un gesto decidido, mientras arregla su desordenado tocado dejando entrever cierta ternura en su mirada. En este último caso nos aproximamos al método pictográfico. Hay un grado de ambigüedad necesario a la imaginación, pero no se interfiere en el tiempo de la narración que sí logra ampliar el momento y el significado iconográfico a partir del gesto. Justamente allí donde Lessing le pide a la pintura que actúe sobre la imaginación, es donde la obra se enriquece (Babbit, 1910: 50):

Pero sólo es fecundo aquello que permite el juego libre de la imaginación. Cuanto más penetramos en una obra de arte, más pensamientos tiene que suscitar ella en nosotros. Cuantos más pensamientos suscite, tanto más firme debe ser nuestra convicción de que estamos penetrando en ella. (Lessing, 1990: 22)

Lessing en ningún momento especifica qué momento debe ser identificado como el más fecundo. En términos estrictos, todo momento de acción es un presente que puede ser proyectado o leído a partir de la capacidad expresiva que lleve consigo. En esa cualidad es donde adquiere su mayor valor la gestualidad. Con el gesto aparece la inmediatez. La respuesta del observador a éste implica la presencia efectiva de la comunicación y, por ende, de la imaginación. El círculo de la obra quedaría así cerrado; el artista entrega un código en su obra que el observador reconoce como propio (Cfr. Gombrich, 1998a: 99). Ambos comulgan en la obra a partir de su verosimilitud, esto es, como tendencia a la aprehensión de una verdad que en el intento se torna infinita. El valor artístico no se basa en la necesidad de conocer la narración sino en que 
ella sea, desde su coherencia interna, verosímil. Así, las lecturas de una obra podrán diferir si no conocemos el argumento representado, pero mientras reconozcamos los rasgos de la emoción, la narración, por diversa que sea, dará prueba de ella.

Lo anterior, nos hace pensar en la distinción que hace Gombrich respecto de los críticos del siglo XVIII, y lo cerca que con ello ubica su teoría del caso particular de Lessing. Desde su perspectiva, para éstos "el arte no era expresión sino que hacía uso de expresiones", otorgándoles un sentido simbólico (Gombrich, 1998b: 25). Si el arte para Lessing sólo hiciese uso de expresiones y éstas no fuesen, por así decirlo, síntomas de la creación artística, entonces Gombrich haría bien en ver en el gesto una simple alegoría de la emoción, entendiendo alegoría en su sentido primigenio, esto es, decir algo distinto de lo que parece (Pächt, 2001: 60). Y así parece mostrarlo Lessing en una primera lectura al decir que a diferencia del poeta, quien puede caracterizar las abstracciones que personifica con nítidas definiciones, el artista, careciendo de estos medios, recurre a símbolos: "Estos símbolos, por el hecho de ser una cosa y significar otra, hacen de estas abstracciones personificadas, figuras alegóricas" (1990: 83).

Dado que Lessing alude a lo invisible o a la necesidad de visualizar las abstracciones, no es problemático que en ellas quede contenida la gestualidad como símbolo. Cuando entendemos, por ejemplo, que las Gracias según Séneca son representadas como alegorías del dar, aceptar y devolver (Wind, 1998: 45), la relación allí se fundamenta pura y exclusivamente en los gestos de los tres personajes para con los otros dos, pero sólo en la medida que imaginamos la acción damos con el valor total de los movimientos corporales, comprendiendo el sentido en el que están dispuestos. Así, la expresión gestual apunta no sólo a la manifestación de una emoción propia del acto representado. No necesitamos de muecas para deducir la alegría que significa aceptar un obsequio, por ejemplo. Simplemente lo asumimos, como también lo hacemos con el rostro que no se nos muestra, el de quien da. La mirada, diría Gombrich, completa la imagen; proyectamos sobre ella a partir de lo que nos insinúa. En otras palabras, imaginamos el ciclo descrito. En su aspecto alegórico, aparentemente enmarcado exclusivamente en la descripción, también podemos hallar un aspecto narrativo. Por lo tanto, aunque las expresiones de las que habla Gombrich parecen fórmulas lingüísticas interjectivas, la unión de dos o más de ellas nos permiten configurar indicios de un relato. La idoneidad de las mismas es aquello que permite la función de la imaginación. En conclusión, Lessing ha unido aquello que Gombrich daba por separado.

Existe otro estudio del historiador en el que caracteriza el método pictográfico diciendo que en él "no hay pretensión [...] de presentar una instantánea de una escena dada tal como podría haber sido vista y fotografiada por un testigo imaginario", poniendo de manifiesto "las falacias de esta concepción del arte [...] que han perseguido a la crítica a partir del Laocoonte de Lessing" (Gombrich, 2000: 88-89). Para Gombrich el énfasis de Lessing en la representación del instante de manera verosímil, condenaría su concepción del arte. El historiador es indiferente respecto a esta condición y desde su perspectiva el hincapié en su relevancia se habría traducido en una idea falsa y errónea del mismo. (Basta pensar en Goethe (1994), para quien las máximas obras de arte muestran la disposición elevada del artista en el reflejo del instante elegido). 
Sin embargo es precisamente en el concepto de verosimilitud de Lessing donde aparece su comunión con el método pictográfico:

La verdad es algo necesario para el espíritu, y sería una tiranía el poner la más mínima traba a la satisfacción de esta necesidad natural del alma humana. La finalidad última de las artes, en cambio, es el placer, y el placer es algo de lo que se puede prescindir. (Lessing, 1990: 15-16)

A pesar de ser prescindible, el placer artístico queda supeditado a la búsqueda de la verdad lessiniana. Según Lessing el hombre se encuentra constantemente en este acto; no vale creer poseerla, sino intentar alcanzarla esforzándose honestamente (Gombrich, 1991: 45). Dicho esfuerzo incita la imaginación sea del creador como del espectador, penetrando y vitalizando la obra. De esta manera la verosimilitud en la pintura, permite esta indagación a partir de la expresión. La certeza que tengamos de la vía que nos entrega una obra de arte, quedará demarcada por los indicios presentados en ella.

Así comprendemos la importancia de la verdad en la similitud. Al igual como la inteligencia tiende hacia ella haciendo de los sentidos un sendero cubierto de parecidos, la obra de arte induce a la imaginación a penetrarla dando al instante una perpetuidad invariable y no representando nada que se conciba como transitorio (Lessing, 1990: 23). La instantánea fotográfica se une al método pictográfico a través de la riqueza otorgada por la imaginación. La forma pictórica ideal que Lessing impone a la creación sería la expresión descriptiva de un episodio cuya narración puede ser imaginada con el fin de evocar una infinitud de cosas, como si en ella quedase arraigada la esperanza de vislumbrar la emoción creativa. Aunque ello podría traer como consecuencia la presencia de ciertos rasgos que aisladamente pueden ser considerados ambiguos dentro de la representación, paradójicamente dicha ambigüedad, solamente en la medida en que se relaciona con otros elementos descriptivos, le permite alcanzar aquello que evoca (Gombrich, 2000: 98-99). Al unir Lessing el símbolo con la alegoría, nos muestra que no es posible en su propuesta distinguir entre el hacer uso de expresiones y ser una expresión artística. Los gestos aparecen como un instante descriptivo para una narración imaginada por el observador: la historia de la amante que dibuja la silueta del amado. Con esto es posible pensar que el método pictográfico de Gombrich comulga con las formas más bellas del instante, surgidas de la acción emotiva. En aquel momento, las exigencias de Lessing y Gombrich no entran en contradicción. 


\section{Conclusiones}

Iniciamos este artículo recordando dos cuadros de William Hogarth que abordan el problema de la representación del instante. En ellos el pintor optaba por dividir la escena en un antes y un después, dejando abierta la interpretación. A partir de la teoría de G.E. Lessing, analizamos las dificultades de dicho tipo de obras, pues el espectador carecía de indicios para completar la narración desde la imaginación y la infinitud de opciones impedía penetrar el instante. Es justamente este rol atribuido por Lessing a la imaginación lo que nos permite vincularlo con E. Gombrich.

Si bien el historiador insisitó en su distancia respecto de la crítica de arte representada por Lessing, el sustento de dicha diferencia radicaría en la idea de verosimilitud exigida por el alemán al arte. Dicha limitación, sería para Gombrich absolutamente irrelevante en la calificación de una obra. De hecho, a través del concepto de método pictográfico propuso la yuxtaposición de momentos en una imagen como mecanismo para evocar una secuencia, alternativa criticada por Lessing.

Ahora bien, más allá de estas innegables diferencias, hemos querido presentar un aspecto común a estos pensadores en el rol otorgado a la imaginación del espectador como complemento narrativo de la obra. Tanto Lessing como Gombrich postulan la grandeza de una pintura en la capacidad de comunicación entre la obra y el observador. En la ambigüedad del instante representado ambos autores reconocen el rasgo central de una obra de arte.

Este artículo recoge los resultados de la investigación "El pensamiento de Ernst Gombrich y el arte no-figurativo" Proyecto Individual $N^{\circ}$ 182.76/2010 financiada por la Vicerrectoría de Investigación y Estudios Avanzados de la Pontificia Universidad Católica de Valparaíso.

\section{Referencias}

Alpers, S. (1976) "Describe or Narrate? A Problem in Realistic Representation". En: New Literary History. Vol.8, No. 1, 15-41.

Babbitt, I. (1910) The New Lakoon. An Essay on the Confution of the Arts. Londres: Constable \& Co.

Carter, A (1924) “Did Lessing Say the Final Word on Description?". En: The English Journal. Vol.13, No. 6, 396-401.

Cassirer, E. (2003)"Eidos ed eidolon. Il problema del bello e dell'arte nei dialoghi platonici". A. Pinotti (trad.). En: Warburg, Aby - Cassirer, Ernst. Il mondo di ieri. Lettere, M. Ghelardi (trad.).Turín: Nino Aragno, 129-168.

Cassirer, E. (1994) Filosofia de la Ilustración, E. Ímaz (trad.). Ciudad de México: Fondo de Cultura Económica.

Chastel, A. (2002) Il gesto nell'arte, D. Pinelli (trad.). Bari: Laterza.

Goethe, W. (1994) "Laocoonte”. En: 'Laocoonte'e altri scritti sull'arte (1789-1805), R. Venuti (trad.). Roma: Salerno, 67-82. 
Gombrich, E. (1991) "El lugar del Laocoonte en la vida y obra de G. E. Lessing (17211781)". En Tributos. Versión cultural de nuestras tradiciones, A. Montelongo (trad.). Ciudad de México: Fondo de Cultura Económica, 29-51.

------. (1998a) "Tradición y expresión en la naturaleza muerta occidental". En: Meditaciones sobre un caballo de juguete, J. M. Valverde (trad.). Madrid: Debate, 95-105.

--------. (1998b) "Metáforas visuales de valor en el arte". En: Meditaciones sobre un caballo de juguete, J. M. Valverde (trad.).Madrid: Debate, 12-29.

-------. (2000) “Acción y expresión en el arte occidental”. En: La imagen y el ojo. Nuevos estudios sobre la psicología de la representación pictórica, A. López Lago y R. Gómez Díaz (trads.).Madrid: Debate, 78-104.

Hogarth, W. (1997) The Analysis of Beauty. New-Haven (Ct.): Yale University Press. Kommerell, M. (1990) Lessing y Aristóteles. Investigación acerca de la teoría de la tragedia, F. Lisi (trad.). Madrid: Visor.

Lee, R. (1940) "Ut Pictura Poesis: The Humanistic Theory of Painting". En: The Art Bulletin. Vol. 22, No. 4, 197-269.

Lessing, G. E .(1990) Laocoonte, E. Barjau (trad.). Madrid: Tecnos.

Morris, D. et al. (1981). Gestures their Origins and Distribution, Londres: Triad/ Granada.

Nichols, J. (1785) Biographical Anecdotes of William Hogarth; with a Catalogue of his Works Chronologically Arrenged; and Occasional Remarks. Londres: John Nichols.

Pächt, O. (2001) Metodo e prassi nella storia dell'arte, F. Cuniberto (trad.). Turín: Bollati Boringhieri.

Settis, S. (1990) La 'Tempestad' interpretada, J. Calatrava Escobar (trad.). Madrid: Akal.

Wind, E. (1998) “Las Gracias de Séneca”, en Los misterios paganos del Renacimiento, J. Sánchez García-Gutiérrez (trad.), Madrid: Alianza. 